\title{
Using low concentration sodium hypochlorite to improve colorectal surgical specimen lymph node harvest
}

\author{
NANRONG YU*, HAIYING LIU* , JIANCHANG LI and SHICAI CHEN \\ Department of Gastrointestinal Tumor Surgery, Affiliated Cancer Hospital and Institute of \\ Guangzhou Medical University, Guangzhou, Guangdong 510095, P.R. China \\ Received February 1, 2019; Accepted January 1, 2020
}

DOI: $10.3892 / \operatorname{mco} .2020 .2018$

\begin{abstract}
Lymph node (LN) retrieval is a critical procedure to determine the pathological stage and adjuvant therapy for colorectal cancer. The present study aimed to recommend a novel method by using sodium hypochlorite to improve colorectal surgical specimen LN harvest. Dissolving time of mesenteric LNs and fat tissue was firstly investigated in different concentrations of sodium hypochlorite. In the sodium hypochlorite group, 65 patients with colorectal cancer who underwent curative surgery were included. After standard manual gross dissection, the mesenteric tissue was subsequently immersed in $1 \%$ sodium hypochlorite for $30 \mathrm{~min}$, and then manual dissection was again applied for additional LN harvest. In the manual method group, 68 patients with colorectal cancer were selected and only manual dissection method was applied for LN harvest. The number of LNs in both groups were recorded for each case. Sodium hypochlorite could dissolve fat tissue significantly faster than LNs and the low concentration sodium hypochlorite had the maximum dissolving time difference between fat tissue and LNs $(\mathrm{P}<0.001)$. After sodium hypochlorite treatment, more LNs were identified when compared with the manual dissection method $(28.2 \pm 12.1$ vs. $16.5 \pm 8.7 ; \mathrm{P}=0.010)$, whereas the number of positive LNs had no significant statistical difference between the two groups $(\mathrm{P}=0.181)$. After sodium hypochlorite immersion, 818 additional LNs $(12.5 \pm 4.8$ per case) were identified and LNs $\leq 2 \mathrm{~mm}$ were $58.4 \%$ (478/818). Moreover, 16 additional metastatic LNs were found in 10 patients. A total of 7 of them were upstaged, including 2 initially N0 cases. Using sodium hypochlorite at low concentrations may be the most simple, rapid, cost-saving,
\end{abstract}

Correspondence to: Dr Shicai Chen, Department of Gastrointestinal Tumor Surgery, Affiliated Cancer Hospital and Institute of Guangzhou Medical University, 78 Hengzhigang Road, Guangzhou, Guangdong 510095, P.R. China

E-mail: cscai2011@163.com

${ }^{*}$ Contributed equally

Key words: sodium hypochlorite, colorectal cancer, lymph nodes nontoxic and effective technique to improve LN harvest in colorectal carcinoma specimens so far. This method should be used routinely regardless of whether the number of LNs is $<12$ or not.

\section{Introduction}

The lymph node (LN) status largely dictates prognosis and adjuvant therapy strategy for colorectal cancer patients. The NCCN guidelines recommend that a minimum of 12 LNs should be dissected to accurately stage colorectal cancer (1). Even though larger LNs are more prone to having metastatic deposits, the presence of metastases could also be identified in small measuring nodes $(1 \mathrm{~mm}, 6.5 \%$; $2 \mathrm{~mm}, 12.4 \%$; $15.3 \%, 3 \mathrm{~mm}$ ) (2). These small LNs are hard to be found and may lead to downstage of tumors. Some patients who might benefit from adjuvant therapy were misclassified as node-negative due to incomplete sampling of LNs (3). Therefore, researchers suggested that more nodes should be examined to increase the likelihood of proper staging (3-6). The number of LNs retrieved from colorectal cancer specimens are influenced by multiple factors, including age of the patient, sex, tumor grade, tumor site, neoadjuvant radiotherapy, operating surgeon and examining pathologist (7-9). One of the most important reasons is that very small LNs are difficult to find, especially amid large amounts of pericolic/perirectal fat.

Various methods mainly concerning fat clearance have been recommended to increase LN harvest (10-14). However, these traditional fat clearance techniques are noxious, time-consuming, costly and troublesome. It cannot be widely used in clinical practice, only for cases in which few LNs are initially identified.

Sodium hypochlorite is the most commonly used irrigating solution in endodontics because of its antimicrobial effect and tissue dissolution capacity. The antimicrobial activity is related to bacterial essential enzymatic sites promoting irreversible inactivation and the chloramination reaction. The dissolution action can be observed in the saponification reaction when sodium hypochlorite degrades lipids and fatty acids resulting in the formation soap and glycerol (15). In this study, we intend to investigate the use of sodium hypochlorite to clear pericolic/perirectal fat and improve harvest of LNs. 


\section{Materials and methods}

Dissolving time of LNs and fat tissue in different concentrations of sodium hypochlorite. The mesentery is now recognised as an organ composed by the tissues of vessels, lymphatic, nerve and adipose (16). Since sodium hypochlorite dissolved organic tissue unselectively, we firstly investigated the dissolving time of different tissues from mesocolon or mesorectum. LNs and fat tissue were obtained from fresh colorectal surgical specimens. LNs diameter (length $\mathrm{x}$ width) measuring about $3 \times 2$ and $10 \times 5 \mathrm{~mm}$ were separately chosen. Because the exposed surface area had a great impact on the dissolving capability of sodium hypochlorite, pericolic/perirectal fat were cut to produce samples of similar size and shape.

Sodium hypochlorite in concentrations of 1, 3 and 5.25\% were commercially purchased and respectively tested at room temperature. Specimens from each group were individually immersed in plastic specimen bags filled with $50 \mathrm{ml}$ of the test solution, then placed without mechanical agitation. The time of complete dissolution of LNs and fat were recorded. These procedures were repeated 5 times.

Properties of LNs after sodium hypochlorite treatment. Alterations of the chemical composition of the dentin have been reported after exposure to sodium hypochlorite (17). Here, we also focused on whether sodium hypochlorite would change the properties of LNs. LNs measuring about $5 \times 5 \mathrm{~mm}$ with possible metastases was immersed in $1 \%$ sodium hypochlorite for $30 \mathrm{~min}$ and then was fixed in $10 \%$ formalin overnight. Afterwards, $4 \mu \mathrm{m}$ sections were cut from the paraffin-embedded blocks for hematoxylin and eosin (H\&E) examination.

Case selection and specimen treatment. Between January 2018 and June 2018, 65 colorectal cancer patients who underwent either open or laparoscopic radical surgery at the Affiliated Cancer Hospital and Institute of Guangzhou Medical University were included in this study. All cases were without distant metastases and had not received preoperative chemoradiotherapy. Patients with recurrent tumors were excluded. The surgical procedure was conducted according to the standard of total or complete mesocolic excision.

LNs of these colorectal resection specimens were firstly harvested by traditional manual gross dissection method. After standard manual gross dissection, the bulk of the mesentery was dissected from the bowel wall and tumor. The mesentery immediately related to the tumour was left in situ since this was to be examined for gross evidence of circumferential resection margin. The tumor/bowel was fixed in $10 \%$ buffered neutral formalin solution for $24 \mathrm{~h}$ before embedded, whereas the entire remaining mesenteric tissue was separately immersed in approximately three times its volume of $1 \%$ sodium hypochlorite for $30 \mathrm{~min}$. After the fat was 'washed' by sodium hypochlorite, manual dissection method was again applied for the visible $\mathrm{LN}$ harvest. In order to reduce opportunity for operator bias in the dissection process, only one experienced staff, S.C., performed dissections both before and after immersion in sodium hypochlorite. The number and size of LNs were recorded for each case. All of the LNs were fixed in $10 \%$ buffered neutral formalin as mentioned above. After paraffin embedding, $4 \mu \mathrm{m}$ thin sections were cut, stained with $\mathrm{H} \& \mathrm{E}$ and then scanned for metastases.

In addition, 68 patients who were treated for colorectal cancer from July 2017 to December 2017 were identified from our collected database. All of these patients were neither with distant metastases nor given chemoradiotherapy before radical operation. Patients with recurrent tumors were also excluded. The manual dissection method without fat clearance was applied to the surgically removed specimens for LN harvest. For these selected patients, the number but not the size of LNs had been recorded.

The present study protocol was approved by The Affiliated Cancer Hospital and Institute of Guangzhou Medical University Ethical Committee. All selected patients provided written statements of their informed consent and the Ethical approval was granted.

Statistical analysis. Statistical analysis was conducted using the statistical software SPSS 17.0 (SPSS, Inc.). Measurement data were compared by the independent-samples t-test or the one-way ANOVA followed by Student-Newman-Keuls post hoc test. The associations between categorical data were performed using the $\chi^{2}$ test. $\mathrm{P}<0.05$ was considered to indicate a statistically significant difference.

\section{Results}

Sodium hypochlorite dissolved fat tissue significantly faster than LNs. The complete dissolving time of small fat tissue $(3 \times 2 \mathrm{~mm})$ in 1,3 and $5.25 \%$ sodium hypochlorite was $13.6 \pm 1.1,6.8 \pm 0.83$ and $5.6 \pm 0.54 \mathrm{~min}$ respectively, while it was $120.6 \pm 5.6,48.0 \pm 1.8$ and $29.0 \pm 3.8 \mathrm{~min}$ respectively for small LNs (Table I). Moreover, the complete dissolving time of bigger fat tissue $(10 \times 5 \mathrm{~mm})$ in 1,3 and $5.25 \%$ sodium hypochlorite was $27.0 \pm 4.0,18.6 \pm 1.1$ and $14.8 \pm 0.83 \mathrm{~min}$, while it was $474.0 \pm 19.4,118.0 \pm 8.3$ and $97.0 \pm 6.7$ min for bigger LNs (Table II). These results indicated that sodium hypochlorite dissolved fat tissue significantly faster than LNs $(\mathrm{P}<0.001)$.

Though high concentration sodium hypochlorite dissolved fat tissue and LNs more quickly than low concentration sodium hypochlorite, the low concentration sodium hypochlorite had the max dissolving time difference between fat tissue and LNs $(\mathrm{P}<0.001$, Table I). So $1 \%$ sodium hypochlorite was chosen for further study in order to avoid rapid destruction of LNs.

Sodium hypochlorite would not change the properties of LNs. $\mathrm{H} \& \mathrm{E}$ staining examination showed that LNs immersed in $1 \%$ sodium hypochlorite would not change their biological characteristics in a short period of time (Fig. 1).

Sodium hypochlorite significantly improved LN harvest. Clinicopathological details in relation to the two different dissection methods were summarized in Table II. There were no significant differences in sex, age, body mass index (BMI), tumour size or tumour location between the two groups $(P>0.05)$. Moreover, no significant association was found when histologic types, $\mathrm{T}$ and $\mathrm{N}$ stage were taken into account $(\mathrm{P}>0.05)$. The very small LNs became easily visible 
Table I. Dissolving time of lymph nodes and fat tissue in different concentrations of sodium hypochlorite (min).

\begin{tabular}{|c|c|c|c|}
\hline $\begin{array}{l}\text { Different concentrations } \\
\text { of sodium hypochlorite }\end{array}$ & Lymph node, mean \pm SD $(n=5)$ & Fat tissue, mean $\pm \operatorname{SD}(n=5)$ & P-value \\
\hline \multicolumn{4}{|l|}{$3 \times 2 \mathrm{~mm}$} \\
\hline $1 \%$ Sodium hypochlorite & $120.6 \pm 5.6$ & $13.6 \pm 1.1$ & $<0.001$ \\
\hline $3 \%$ Sodium hypochlorite & $48.0 \pm 1.8$ & $6.8 \pm 0.83$ & $<0.001$ \\
\hline $5.25 \%$ Sodium hypochlorite & $29.0 \pm 3.8$ & $5.6 \pm 0.54$ & $<0.001$ \\
\hline P-value ${ }^{b}$ & $<0.001$ & $<0.001$ & \\
\hline \multicolumn{4}{|l|}{$10 \times 5 \mathrm{~mm}$} \\
\hline $1 \%$ Sodium hypochlorite & $474.0 \pm 19.4$ & $27.0 \pm 4.0$ & $<0.001$ \\
\hline $3 \%$ Sodium hypochlorite & $118.0 \pm 8.3$ & $18.6 \pm 1.1$ & $<0.001$ \\
\hline $5.25 \%$ Sodium hypochlorite & $97.0 \pm 6.7$ & $14.8 \pm 0.83$ & $<0.001$ \\
\hline P-value ${ }^{b}$ & $<0.001$ & $<0.001$ & \\
\hline
\end{tabular}

at-test; bone-way ANOVA.

Table II. Clinicopathological features of patients included.

\begin{tabular}{|c|c|c|c|}
\hline Variables & $\begin{array}{l}\text { Sodium hypochlorite } \\
\text { group }(n=65)\end{array}$ & $\begin{array}{l}\text { Manual method } \\
\text { group }(n=68)\end{array}$ & P-value \\
\hline Sex & & & 0.929 \\
\hline Male & $32(49.2 \%)$ & $34(50.0 \%)$ & \\
\hline Female & $33(50.8 \%)$ & $34(50.0 \%)$ & \\
\hline Age, years & $56.6 \pm 11.3$ & $56.2 \pm 11.8$ & 0.568 \\
\hline BMI & $21.2 \pm 4.7$ & $20.7 \pm 4.6$ & 0.851 \\
\hline Tumor size, $\mathrm{cm}$ & $4.3 \pm 1.8$ & $4.1 \pm 1.6$ & 0.414 \\
\hline Location & & & 0.832 \\
\hline Right colon & $16(24.6 \%)$ & $20(29.4 \%)$ & \\
\hline Transverse colon & $3(4.6 \%)$ & $4(5.9 \%)$ & \\
\hline Left colon & $6(9.2 \%)$ & $9(13.2 \%)$ & \\
\hline Sigmoid colon & $20(30.8 \%)$ & $17(25.0 \%)$ & \\
\hline Rectum & $20(30.8 \%)$ & $18(26.5 \%)$ & \\
\hline Histologic type & & & 0.651 \\
\hline Well differentiated adenocarcinoma & $27(41.5 \%)$ & $23(33.8 \%)$ & \\
\hline Moderately differentiated adenocarcinoma & $24(36.9 \%)$ & $29(42.6 \%)$ & \\
\hline Poorly differentiated adenocarcinoma & $14(21.5 \%)$ & $16(23.5 \%)$ & \\
\hline T stage & & & 0.818 \\
\hline $\mathrm{T} 1$ & $5(7.7 \%)$ & $5(7.4 \%)$ & \\
\hline $\mathrm{T} 2$ & $13(20.0 \%)$ & $16(23.5 \%)$ & \\
\hline $\mathrm{T} 3$ & $23(35.4 \%)$ & $19(27.9 \%)$ & \\
\hline $\mathrm{T} 4$ & $24(36.9 \%)$ & $28(41.2 \%)$ & \\
\hline $\mathrm{N}$ stage & & & 0.166 \\
\hline No & $14(21.5 \%)$ & $16(23.5 \%)$ & \\
\hline N1 & $24(36.9 \%)$ & $34(50.0 \%)$ & \\
\hline $\mathrm{N} 2$ & $27(41.5 \%)$ & $18(26.5 \%)$ & \\
\hline Total lymph node harvest & $28.2 \pm 12.1$ & $16.5 \pm 8.7$ & 0.010 \\
\hline Positive lymph node harvest & $3.0 \pm 2.3$ & $2.3 \pm 2.1$ & 0.181 \\
\hline
\end{tabular}

after sodium hypochlorite treatment (Fig. 2). When the total number of LNs was compared, the sodium hypochlorite group increased more LN harvest than manual method group $(28.2 \pm 12.1$ vs. $16.5 \pm 8.7, \mathrm{P}=0.010)$. However, the number of 
Table III. Changes in the staging of 10 patients after sodium hypochlorite treatment.

\begin{tabular}{ccccc}
\hline Case & $\begin{array}{c}\text { Number of LNs (+) before sodium } \\
\text { hypochlorite treatment }\end{array}$ & Initial N stage & $\begin{array}{c}\text { Number of extra LNs (+) after } \\
\text { sodium hypochlorite treatment }\end{array}$ & Final N stage \\
\hline 1 & 3 & N1b & 3 & N2a \\
2 & 3 & N1b & 1 & N2a \\
3 & 4 & N2a & N2a & N1a \\
4 & 0 & N0 & 2 & N2b \\
5 & 0 & N0 & 2 & N2b \\
6 & 6 & N2a & 1 & N2b \\
7 & 6 & N2a & 2 & N2a \\
9 & 5 & N2a & 2 & N2a \\
\hline
\end{tabular}

LNs, lymph nodes.

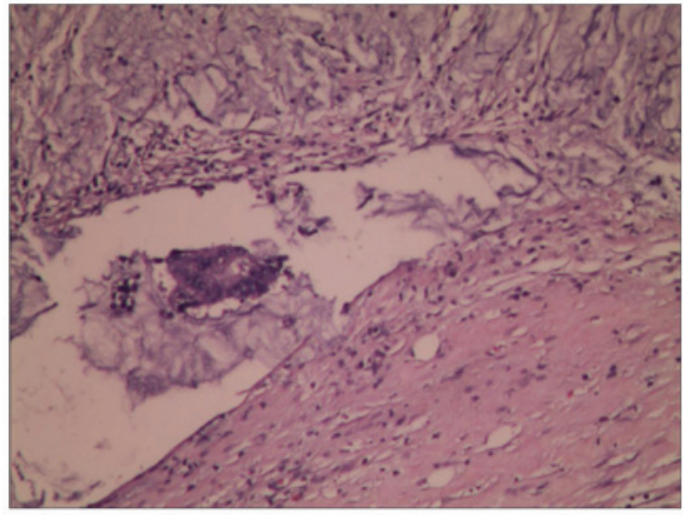

Figure $1 . H \& E$ examination indicated tumor cell infiltration in the lymph nodes after $1 \%$ sodium hypochlorite treatment for $30 \mathrm{~min}$. Magnification, $\mathrm{x} 100 . \mathrm{H} \& \mathrm{E}$, hematoxylin and eosin.

positive LNs did not increase in the sodium hypochlorite group when compared with manual method group $(\mathrm{P}=0.181)$.

Within the sodium hypochlorite group, a total of $1,020 \mathrm{LNs}$ $(15.6 \pm 8.7$ per case) were revealed in initial inspection. After treated in sodium hypochlorite for $30 \mathrm{~min}, 818$ additional LNs $(12.5 \pm 4.8$ per case) were identified, which account for $44.5 \%$ of all the LNs revealed in this group (Fig. 3). LNs $\leq 2 \mathrm{~mm}$ were $9.6 \%(98 / 1,020)$ and $58.4 \%$ (478/818) separately before and after sodium hypochlorite treatment. Use of sodium hypochlorite method could obviously increase LN harvest, especially those smaller than $2 \mathrm{~mm}$ (Fig. 3).

After treated with sodium hypochlorite, 16 additional metastatic LNs were found in 10 patients. Seven of the 10 patients were upstaged, including 2 initially NO cases (Table III).

\section{Discussion}

LN size may not be a reliable indicator for $\mathrm{LN}$ metastasis. Studies had showed that most nodal metastases in colorectal cancer were found in small LNs ( $5 \mathrm{~mm}$ or less in diameter) which were often missed during routine dissection of specimens (2,18-21). Brown et al even reported that $75 \%$ of all

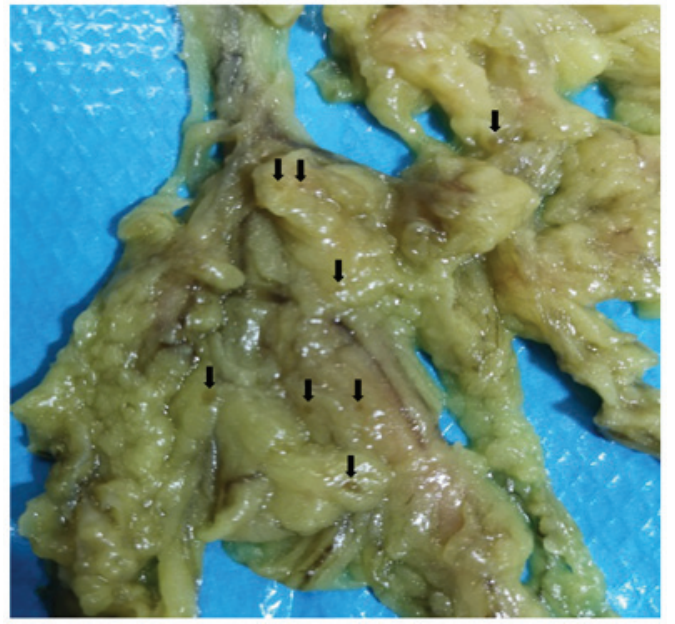

Figure 2 . Very small lymph nodes were easily visible after $1 \%$ sodium hypochlorite treatment for $\sim 30 \mathrm{~min}$. The black arrows indicate very small lymph nodes.

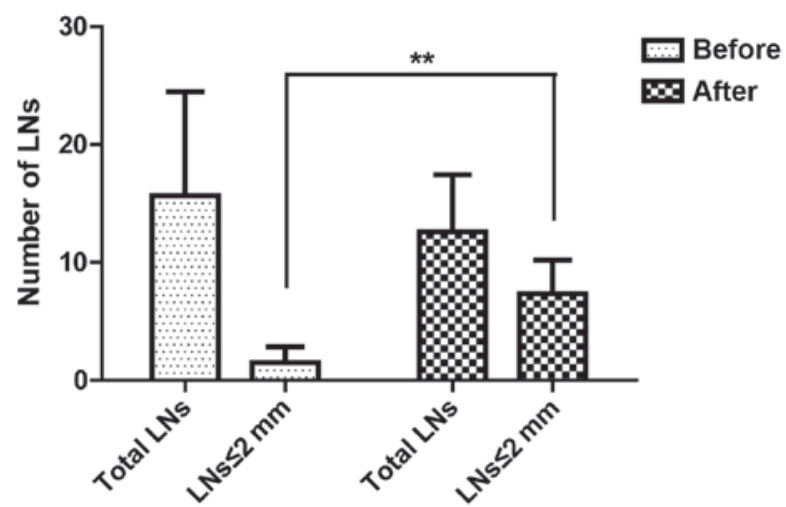

Figure 3. Sodium hypochlorite increased LN harvest, especially those $<2 \mathrm{~mm} .{ }^{* *} \mathrm{P}<0.01$. LN, lymph node.

positive nodes were under $2 \mathrm{~mm}$ in size (6). Furthermore, the total number of LNs investigated was considered an independent risk factor no matter metastases were present or not (22). 
Thus, the detection of the largest possible number of LNs and a complete pathologic assessment of nodal status are essential for accurate staging, therapeutic decisions, and prognosis of patients $(3,23)$.

Manual LN dissection is the current standard method at most institutions and it depends on visual isolation and palpation of the mesenteric tissue. It is certainly that smaller LNs could be found using manual techniques by experienced personnel who take appropriate time. Sampling the entire pericolic fat is theoretically the most accurate method for total lymph node examination. However, very small lymph nodes are rarely found and it requires time, money and is not practical in routine surgical pathology $(11,24,25)$. So, many researchers suggested that additional techniques combined with manual dissection could help to increase small LN harvest more easily. Fat clearance method has been recently recommended for the detection of small or inconspicuous LNs. However, this technique requires the use of sequential immersions of the mesenteric tissue in baths of alcohol, xylene, followed by methyl salicylate. These solutions are noxious and the fat has to be dissected in a ventilated cabinet using transillumination to locate the LNs. In addition, the clearance process takes dozens of hours or even weeks and causes an unacceptable reporting delay $(10,26)$. Furthermore, serial sectioning of the cleared mesenteric tissue at 1-2 mm intervals is necessary to reveal small LNs. Nodes may be probably cut into 2 halves during multilevel step sectioning process, resulting in error of LN count. The disadvantages of fat clearance precludes its use in routine pathological assessment, only for cases in which an unacceptably low number of LNs are retrieved (27).

Other techniques such as LN revealing solution $(11,28)$, sentinel node procedures with methylene blue injection (29), and fat-dissociation method using enzymes (25) are applied to increase the yield of LNs. However, these methods are not used routinely largely because they are hazardous, time-consuming and expensive and do not provide rapid pathology report.

Sodium hypochlorite is still the most commonly used irrigation solution for endodontic procedures because of their characteristics such as wide-spectrum antimicrobial activity and organic tissue dissolution capacity (17). The tissue-dissolving capability of sodium hypochlorite relies on its concentration, volume, contact time of the solution, the surface area of the exposed tissue, $\mathrm{pH}$, temperature, and mechanical agitation (30,31). Here, we showed that sodium hypochlorite could easily dissolve fat tissue when compared with LNs even in a low concentration at room temperature without agitation.

High concentrations may be more toxic and dissolve the whole mesenteric tissue with no dissolving time difference, while the low concentration sodium hypochlorite has the maximum dissolving time difference between fat tissue and LNs. In addition, H\&E examination indicated that low concentration sodium hypochlorite avoided changes in tissue composition of LNs. This study found that the use of sodium hypochlorite at lower concentration, such as $1 \%$, demonstrated to be effective in promoting a suitable dissolution of mesenteric fat and preventing a pronounced damage to LNs.

We had showed that $1 \%$ sodium hypochlorite had the maximum dissolving time difference between fat tissue and LNs, and the complete dissolving time of bigger fat tissue $(10 \times 5 \mathrm{~mm})$ in $1 \%$ sodium hypochlorite was about $30 \mathrm{~min}$
$(27.0 \pm 4.0 \mathrm{~min}$, Table I) without change in the properties of LNs. So, we considered that $30 \mathrm{~min}$ would be the appropriate processing time. After $1 \%$ sodium hypochlorite immersion for about $30 \mathrm{~min}$, the perienteric adipose tissue was cleared and the LNs were easily visible. The sodium hypochlorite group detected more LNs in total than manual dissection method group. More LNs harvest means more accurate pathological staging. Though the number of positive LNs did not significantly increase after sodium hypochlorite treatment, this method is still meaningful because it is not a question about 'significant statistical difference' but a question about 'have or have no'. Even a single additional LN metastasis identified will be sufficient to upstage the malignancy from $\mathrm{pN} 0$ to $\mathrm{pN} 1$ when adjuvant therapy is required.

Furthermore, 818 additional LNs were revealed after sodium hypochlorite treatment, which account for $44.5 \%$ of all the LNs found in sodium hypochlorite group. In line with other assistant techniques $(6,32)$, sodium hypochlorite solution was greatly helpful in detecting small LNs and most of these additional LNs (58.4\%) were smaller than $2 \mathrm{~mm}$. Besides, 16 additional metastatic LNs were found in 10 cases after sodium hypochlorite treatment and the stage of the disease was upgraded in 7 of the 10 cases. More importantly, additional metastatic LNs had been found in 2 initially pN0 cases, resulting in upstaging from TNM stage II to stage III, implying that postoperative adjuvant chemotherapy had to be given.

However, there were still some limits in our research. The sample number of this study was small. Also, because it was a retrospective study, the size of lymph nodes for the control group had not been recorded before and the data cannot be gathered. In order to reduce opportunity for operator bias in the dissection process, only one experienced person performed dissections both before and after immersion in sodium hypochlorite.

For the first time, this study indicates that sodium hypochlorite at low concentration can be used to reveal LNs in colorectal carcinoma specimens. As we know, it may be the most simple, rapid (30 min), cost-saving (US \$1.0), nontoxic and effective method to improve LN harvest so far. We suggest that sodium hypochlorite after manual dissection should be used routinely regardless of whether the number of LNs is less than 12 or not.

\section{Acknowledgements}

Not applicable.

\section{Funding}

No funding was received.

\section{Availability of data and materials}

All data generated or analyzed during this study are included in this published article.

\section{Authors' contributions}

NY and HL conceived and designed the present study, and gave final approval. JL and SC contributed to the data analysis and 
interpretation. SC was responsible for provision of the study material and wrote the manuscript. All of the authors revised the manuscript critically. All authors read and approved the final draft of the manuscript.

\section{Ethics approval and consent to participate}

The present study protocol was approved by The Affiliated Cancer Hospital and Institute of Guangzhou Medical University Ethical Committee. All selected patients provided written statements of their informed consent and the Ethical approval was granted.

\section{Patient consent for publication}

Not applicable.

\section{Competing interests}

The authors declare that they have no competing interests.

\section{References}

1. Benson AB III, Venook AP, Cederquist L, Chan E, Chen YJ, Cooper HS, Deming D, Engstrom PF, Enzinger PC, Fichera A, et al: Colon cancer, version 1.2017, NCCN Clinical Practice Guidelines in Oncology. J Natl Compr Canc Netw 15: 370-398, 2017.

2. Murphy J, O'Sullivan GC and Fitzgibbon J: The effect of node size on the detection of nodal metastases in Dukes $\mathrm{C}$ rectal carcinoma. Gut 44: A84, 1999

3. Tepper JE, O'Connell MJ, Niedzwiecki D, Hollis D, Compton C, Benson AB III, Cummings B, Gunderson L, Macdonald JS and Mayer RJ: Impact of number of nodes retrieved on outcome in patients with rectal cancer. J Clin Oncol 19: 157-163, 2001.

4. Goldstein NS, Sanford W, Coffey M and Layfield LJ: Lymph node recovery from colorectal resection specimens removed for adenocarcinoma. Trends over time and a recommendation for a minimum number of lymph nodes to be recovered. Am J Clin Pathol 106: 209-216, 1996.

5. Kim YW, Kim NK, Min BS, Lee KY, Sohn SK and Cho CH: The influence of the number of retrieved lymph nodes on staging and survival in patients with stage II and III rectal cancer undergoing tumor-specific mesorectal excision. Ann Surg 249: 965-972, 2009.

6. Brown HG, Luckasevic TM, Medich DS, Celebrezze JP and Jones SM: Efficacy of manual dissection of lymph nodes in colon cancer resections. Mod Pathol 17: 402-406, 2004.

7. Sarli L, Bader G, Iusco D, Salvemini C, Mauro DD, Mazzeo A, Regina $G$ and Roncoroni L: Number of lymph nodes examined and prognosis of TNM stage II colorectal cancer. Eur J Cancer 41: 272-279, 2005

8. Valsecchi ME, Leighton J Jr and Tester W: Modifiable factors that influence colon cancer lymph node sampling and examination. Clin Colorectal Cancer 9: 162-167, 2010.

9. Baxter NN, Morris AM, Rothenberger DA and Tepper JE: Impact of preoperative radiation for rectal cancer on subsequent lymph node evaluation: A population-based analysis. Int J Radiat Oncol Biol Phys 61: 426-431, 2005.

10. Scott KW and Grace RH: Detection of lymph node metastases in colorectal carcinoma before and after fat clearance. Br J Surg 76: 1165-1167, 1989.

11. Koren R, Siegal A, Klein B, Halpern M, Kyzer S, Veltman V and Gal R: Lymph node-revealing solution: Simple new method for detecting minute lymph nodes in colon carcinoma. Dis Colon Rectum 40: 407-410, 1997.

12. Wang H, Safar B, Wexner SD, Denoya P and Berho M: The clinical significance of fat clearance lymph node harvest for invasive rectal adenocarcinoma following neoadjuvant therapy. Dis Colon Rectum 52: 1767-1773, 2009.

13. Newell KJ, Sawka BW, Rudrick BF and Driman DK: GEWF solution. Arch Pathol Lab Med 125: 642-645, 2001.
14. Prabhudesai AG, Dalton R, Kumar D and Finlayson CJ: Mechanised one-day fat clearance method to increase the lymph node yield in rectal cancer specimens. Br J Biomed Sci 62: 120-123, 2005.

15. Estrela C, Estrela CR, Barbin EL, Spano JC, Marchesan MA and Pecora JD: Mechanism of action of sodium hypochlorite. Braz Dent J 13: 113-117, 2002.

16. Coffey JC and O'Leary DP: The mesentery: Structure, function, and role in disease. Lancet Gastroenterol Hepatol 1: 238-247, 2016.

17. Tartari T, Bachmann L, Maliza AG, Andrade FB, Duarte MA and Bramante CM: Tissue dissolution and modifications in dentin composition by different sodium hypochlorite concentrations. J Appl Oral Sci 24: 291-298, 2016.

18. Herrera-Ornelas L, Justiniano J, Castillo N, Petrelli NJ, Stulc JP and Mittelman A: Metastases in small lymph nodes from colon cancer. Arch Surg 122: 1253-1256, 1987.

19. Rodriguez-Bigas MA, Maamoun S, Weber TK, Penetrante RB, Blumenson LE and Petrelli NJ: Clinical significance of colorectal cancer: Metastases in lymph nodes $<5 \mathrm{~mm}$ in size. Ann Surg Oncol 3: 124-130, 1996.

20. Haboubi NY, Abdalla SA, Amini S, Clark P, Dougal M, Dube A and Schofield P: The novel combination of fat clearance and immunohistochemistry improves prediction of the outcome of patients with colorectal carcinomas: A preliminary study. Int J Colorectal Dis 13: 99-102, 1998.

21. Monig SP, Baldus SE, Zirbes TK, Schröder W, Lindemann DG, Dienes HP and Hölscher AH: Lymph node size and metastatic infiltration in colon cancer. Ann Surg Oncol 6: 579-581, 1999.

22. Le VoyerTE, Sigurdson ER, Hanlon AL, Mayer RJ, Macdonald JS, Catalano PJ and Haller DG: Colon cancer survival is associated with increasing number of lymph nodes analyzed: A secondary survey of intergroup trial INT-0089. J Clin Oncol 21: 2912-2919, 2003.

23. Washington MK: Colorectal carcinoma: Selected issues in pathologic examination and staging and determination of prognostic factors. Arch Pathol Lab Med 132: 1600-1607, 2008.

24. Kim YM, Suh JH, Cha HJ, Jang SJ, Kim MJ, Yoon S, Kim B, Chang H, Kwon Y, Hong EK and Ro JY: Additional lymph node examination from entire submission of residual mesenteric tissue in colorectal cancer specimens may not add clinical and pathologic relevance. Hum Pathol 38: 762-767, 2007.

25. Fujino S, Miyoshi N, Ohue M, Noura S, Tomita Y, Yano M and Sakon M: New enhanced and effective method for staging cancer to detect lymph nodes after fat-dissociation. Oncol Rep 32: 922-926, 2014.

26. Haboubi NY, Clark P, Kaftan SM and Schofield PF: The importance of combining xylene clearance and immunohistochemistry in the accurate staging of colorectal carcinoma. J R Soc Med 85: 386-388, 1992.

27. Compton CC, Fielding LP, Burgart LJ, Conley B, Cooper HS, Hamilton SR, Hammond ME, Henson DE, Hutter RV, Nagle RB, et al: Prognostic factors in colorectal cancer. College of American pathologists consensus statement 1999. Arch Pathol Lab Med 124: 979-994, 2000.

28. Vogel C, Kirtil T, Oellig F and Stolte M: Lymph node preparation in resected colorectal carcinoma specimens employing the acetone clearing method. Pathol Res Pract 204: 11-15, 2008.

29. Markl B, Kerwel TG, Wagner T, Anthuber M and Arnholdt HM: Methylene blue injection into the rectal artery as a simple method to improve lymph node harvest in rectal cancer. Mod Pathol 20: 797-801, 2007.

30. Moorer WR and Wesselink PR: Factors promoting the tissue dissolving capability of sodium hypochlorite. Int Endod J 15: 187-196, 1982 .

31. Christensen CE, McNeal SF and Eleazer P: Effect of lowering the $\mathrm{pH}$ of sodium hypochlorite on dissolving tissue in vitro. J Endod 34: 449-452, 2008.

32. Ma XL, Ye JX, Su J, Qi FF, Meng QY and Shi XY: A modified GEWF solution is cost-saving and effective for lymph node retrieval in resected colorectal carcinoma specimens. Pathol Res Pract 210: 543-547, 2014. 